\title{
Communication and patient safety in gynecology and obstetrics - study protocol of an intervention study
}

Sonia Lippke ${ }^{1 *} \mathbb{D}$, Julian Wienert ${ }^{1} \mathbb{D}$, Franziska Maria Keller ${ }^{1}$, Christina Derksen ${ }^{1} \mathbb{D}$, Annalena Welp ${ }^{1} \mathbb{D}$, Lukas Kötting ${ }^{1}$, Kerstin Hofreuter-Gätgens ${ }^{2}$, Hardy Müller ${ }^{2,3}$, Frank Louwen ${ }^{4}$, Marcel Weigand ${ }^{3}$, Kristina Ernst ${ }^{5}$, Katrina Kraft ${ }^{5}$, Frank Reister ${ }^{6}$, Arkadius Polasik ${ }^{6}$, Beate Huener nee Seemann ${ }^{6}$, Lukas Jennewein ${ }^{4}$, Christoph Scholz ${ }^{6}$ and Annegret Hannawa ${ }^{7}$

\begin{abstract}
Background: Patient safety is a key target in public health, health services and medicine. Communication between all parties involved in gynecology and obstetrics (clinical staff/professionals, expectant mothers/patients and their partners, close relatives or friends providing social support) should be improved to ensure patient safety, including the avoidance of preventable adverse events (pAEs). Therefore, interventions including an app will be developed in this project through a participatory approach integrating two theoretical models. The interventions will be designed to support participants in their communication with each other and to overcome difficulties in everyday hospital life. The aim is to foster effective communication in order to reduce the frequency of pAEs. If communication is improved, clinical staff should show an increase in work satisfaction and patients should show an increase in patient satisfaction.
\end{abstract}

Methods: The study will take place in two maternity clinics in Germany. In line with previous studies of complex interventions, it is divided into three interdependent phases. Each phase provides its own methods and data. Phase 1: Needs assessment and a training for staff $(n=140)$ tested in a pre-experimental study with a pre/post-design. Phase 2: Assessment of communication training for patients and their social support providers $(n=423)$ in a randomized controlled study. Phase 3: Assessment of an app supporting the communication between staff, patients, and their social support providers $(n=423)$ in a case-control study. The primary outcome is improvement of communication competencies. A range of other implementation outcomes will also be assessed (i.e. pAEs, patient/treatment satisfaction, work satisfaction, safety culture, training-related outcomes).

Discussion: This is the first large intervention study on communication and patient safety in gynecology and obstetrics integrating two theoretical models that have not been applied to this setting. It is expected that the interventions, including the app, will improve communication practice which is linked to a lower probability of pAEs. The app will offer an effective and inexpensive way to promote effective communication independent of users' motivation. Insights gained from this study can inform other patient safety interventions and health policy developments.

Trial registration: ClinicalTrials.gov Identifier: NCT03855735; date of registration: February 27, 2019.

Keywords: Preventable adverse events, Patient safety, Communication competences, Midwifery models of care, HAPA, Participatory intervention development, Digitization, App, eHealth, Health services research

\footnotetext{
* Correspondence: s.lippke@jacobs-university.de

'Jacobs University Bremen gGmbH, Germany Campus Ring 1, 28759 Bremen,

Germany

Full list of author information is available at the end of the article
}

(c) The Author(s). 2019 Open Access This article is distributed under the terms of the Creative Commons Attribution 4.0 International License (http://creativecommons.org/licenses/by/4.0/), which permits unrestricted use, distribution, and reproduction in any medium, provided you give appropriate credit to the original author(s) and the source, provide a link to the Creative Commons license, and indicate if changes were made. The Creative Commons Public Domain Dedication waiver (http://creativecommons.org/publicdomain/zero/1.0/) applies to the data made available in this article, unless otherwise stated. 


\section{Background}

Patient safety is a key target in public health, health services, and medicine $[1,2]$. In addition to medical skills and knowledge, communication has been shown to be a major contributor to patient safety, both within the healthcare team and between healthcare professionals and patients [3-5]. Communication, not only between different professionals, but also between staff members and patients or relatives, is a significant part in clinical routine each day. Important information may be lost because of the use of medical terms and may result in reduced patient safety, especially when medical terms are used with patients and their partners and relatives [3-5].

Different communication errors and barriers to effective communication have been identified in parts of the clinical team. Errors, such as the omission of important information, describe the kind of suboptimal communication behaviors, whereas barriers are obstructions to engaging in effective communication behaviors and include organizational and (inter-) personal factors such as rapidly changing healthcare teams, work overload, lack of mutual respect, not feeling part of the team, lack of self-confidence, and lack of training [6]. In a review [7] it was summarized that "effective clinical communication is respectful, clear, direct, and explicit. Consistent execution of successful communication requires excellent listening skills, superb administrative support, and collective commitment to move past traditional hierarchy and professional stereotyping."

Studies have shown that in clinical settings, poor communication may be responsible for up to $80 \%$ of all preventable adverse events (pAEs; e.g. [4]), which are events affecting patient safety that are caused by unsafe healthcare processes, rather than by the medical condition of the patient [2]. PAEs can occur in all clinical specialties, including gynecology and obstetrics $[9,18]$. Besides communication between healthcare providers, many studies have demonstrated that suboptimal doctor-patient communication is related to pAEs, including medical errors [35]. Not only is it important to communicate or disclose medical errors to patients appropriately [10] but also to communicate (more) safely and effectively in general [11]. In obstetrics, clinical routine is challenging due to high workload and risks of emergency calls (e.g., due to emergency caesarean section) as well as because medical staff is always responsible for both the mother and the fetus/newborn.

A typical example of a pAE in gynecology and obstetrics is the confusion of maternal and infant pulse rates during childbirth, which could result in life-long damage to the fetus due to asphyxia during childbirth (damage case analyses by [12]). This pAE may be caused by the ineffective use of available resources due to poor communication between the different partners (staff, patients and their accompanying persons/ social support providers, [13]). PAEs in gynecology and obstetrics include any physical or mental injury to the pregnant woman, fetus, or newborn due to poor communication, which may lead to incorrect medical decisions causing stillbirths, perinatal, neonatal or maternal mortality, unplanned caesarean sections, neonatal morbidity, blood loss, and hemorrhage [8].

With regard to the prevalence of pAEs, an observation study conducted in obstetrics and gynecology by November et al. in Boston, USA, identified forty-one pAEs within a time frame of 12-weeks [14]. In a recent international metaanalysis by Tanaka, Eriksson and Obermair, the incidence of adverse events in gynecological hospital admissions was $10.8 \%$ [15]. Of these adverse events, $52.5 \%$ could have been prevented and $1.2 \%$ resulted in death. The authors note that "preventability can only be assessed from available documentation and can be influenced by study personnel experience, and knowledge [ ...] amendments [ ...] need to take place to improve healthcare delivery in gynecology" (p. 198f). Improved communication is also likely to result in better healthcare provider and patient outcomes. For instance, a recent study has discussed the importance of communication between healthcare professionals and physician well-being. Physician burnout was associated with an increased risk for unsafe care, unprofessional behaviors, and low patient satisfaction [16-18]. This is especially true when under time constraints $[6,19,20]$.

Patient satisfaction is an important patient-centric outcome for a gynecological clinic and its staff. Giving birth can be a positive experience but it can also be painful. The more pain a mother experiences and the longer her convalescence lasts, the more it affects her satisfaction. Despite healthcare providers' awareness of this relationship, there is still room for improvement in pain treatment during labor [21]. Effective communication is one key in pain management, especially under high stress and demands. Accordingly, this needs to be improved based on empirical evidence. Empirical evidence on the effectiveness of communication training is ambiguous. Several studies show that communication errors and barriers can be reduced by efficient training programs that help individuals to identify, prevent or manage such errors and barriers. For instance, one study demonstrated that a standardized team-training program for healthcare professionals in obstetric units, based on an analysis of common causes for adverse events, was found to successfully raise professionals' confidence in dealing with complex emergency situations [12]. Perceived ownership of staff has been demonstrated to be the key moderator of the effectiveness of such trainings [22]. However, a recent systematic review concluded that "Current evidence is inadequate to inform content of training or practice"[9]. Thus, communication between professionals and with patients should be structured [23, 24] specifically to the specific 
context. The primary aim of our project, which is theoretically grounded in models of health-related communication [11] and behavioral change (HAPA) [25], is to improve communication behaviors in gynecology and obstetrics. The second aim is to reduce pAEs and increase healthcare provider and patient satisfaction.

\section{Communication}

A multitude of models of communication in healthcare exists. Accurate, clear communication is central to all of them. For instance, communication is one of four central aspects in the TeamStepps framework of teamwork in healthcare, which has been validated in many clinical settings, including obstetrics [26-28]. The communication dimension of this framework utilizes different tools to facilitate communication between healthcare providers, particularly in critical situations like emergencies or handovers. These tools include check-back (or closedloop communication) to ensure the recipient has understood the sender's information correctly, callout, which is used to convey critical information to a larger group of people efficiently, SBAR (an acronym standing for situation, background, assessment and recommendation), which can be used when requesting help in emergency situations, and a checklist for handovers [29]. The importance of sufficient, accurate and clear conveyance of information is also represented in the SACCIA model by Hannawa [11]. The acronym "SACCIA" stands for five core competencies that constitute safe communication in healthcare: "Sufficiency", "Accuracy", "Clarity", "Contextualization" and "Interpersonal Adaptation". The model has been used to classify communication causes of critical incidents, and it explains how communication errors put patient safety at risks [30].

According to the SACCIA model, focusing on transporting factual information is necessary for effective communication, but not sufficient, especially in obstetrics. Communication, and interpersonal/relational dimensions in particular, have also been identified as one of four dimensions in midwifery models of care. In obstetrics, the biomedical or pathogenic approach to patient care adopted by physicians may clash with nurses' or midwives' salutogenetic approaches [31]. These models consider that - unlike most other reasons to visit a hospital - birth is a natural process in most cases and a joyful moment for the parents, but it can also cause uncertainty or fear. Thus, consideration of interpersonal or relational aspects of communication with the expectant mother - such as being respectful of and taking her emotions into account is essential to transport important information to and from the mother and accompanying persons. Moreover, focusing on interpersonal communication with other team members is likely to improve team functioning [32] and thus increase team members' motivation to engage in more technical communication.

In addition, the model of relational coordination (communication between healthcare providers) and relational coproduction (communication between healthcare provider and patient, [33]) is defined as 'a mutually reinforcing process of communicating and relating for the purpose of task integration' ([34], p. 301). It combines the technical dimensions of communication (frequent, timely, accurate, and problem-solving) with interpersonal communication goals (shared goals, shared knowledge, and mutual respect [35]). The relational aspect of this model has been adapted to the communicative process of decision-making between midwives and expectant mothers as a response to the critique that informed choice or shared decision models rely too much on factual information without taking the context or conversation partner into account [36].

If the communication competencies are practiced adequately, the quality of healthcare communication is increased and, as a result, risk of pAEs is reduced. [11]. This objective can be achieved through training sessions, and digitization (telehealth, eHealth, mHealth) [37] opens new avenues, especially in times of work concentration due to efficiency increasing, skills shortage due to few experts on the labor market, and multi-tasking as a societal trend $[2,16,17]$. There are multiple advantages to digital training, such as adaptability to the user's needs [38], just-in-time-interventions [37] and a high number of potential users who are motivated to participate due to technological interests instead of the content, making it easier to reach rather unmotivated individuals $[39,40]$.

\section{Behavioral change}

While the models described above $[33,36]$ provide theoretical frameworks describing communication, they do not explain how effective communication behaviors can be implemented into daily practice. For instance, the inconsistency between knowledge about pain management and actual pain management described above begs the question why mothers are not treated more adequately if professionals know about the relationship between pain and patient satisfaction. The Health Action Process Approach (HAPA) [25] model describes how to translate the intention/motivation to adopt a new behavior into actually adopting the behavior, and specifically takes the role of motivation and awareness of a situation into account. The HAPA model has been found useful to describe, explain and successfully improve behaviors in a variety of settings, particularly in healthcare and preventive settings [38-42]. Modules for trainings and interventions can be developed and structured based on the HAPA model (Fig. 1). 
The HAPA model suggests a distinction between the (a) motivational phase that leads to a behavioral goal intention/motivation, followed by the (b) volitional phase that leads to the actual health behavior [41]. Within the two phases, different patterns of socialcognitive predictors may emerge (see Fig. 1). In the initial motivation phase (a), a person develops an intention to act. In this phase, risk perception is seen as a distal antecedent (e.g., "I am at risk for poor communication"). Risk perception in itself is insufficient to enable a person to form an intention. Rather, it sets the stage for a contemplation process and further elaboration of thoughts about consequences and competences. Similarly, positive outcome expectancies (e.g., "If I communicate effectively, I will reduce my risk for adverse events and being unsatisfied") are most relevant in the motivation phase when a person evaluates the pros and cons of certain behavioral outcomes. One needs to believe in their capability to perform a desired action, which is conceptualized as perceived self-efficacy (e.g., "I am capable to communicate effectively in spite of the high time pressure or difficult communication partners"). Perceived self-efficacy operates in concert with positive outcome expectancies, both of which substantially contribute to forming an intention. Both beliefs are needed for forming intentions to adopt difficult behaviors, such as effective communication. After forming an intention, the volitional phase (b) is entered.

When a person is inclined to adopt a particular health behavior, the 'good intention' has to be transformed into detailed (self-)instructions on how to perform the desired action by means of planning [43]. Once an action has been initiated, it has to be maintained. This is not achieved through a single act of will but involves ongoing use of self-regulatory skills and strategies. Thus, the volitional phase should be further broken down into more proximal factors, such as planning, self-efficacy, and social support. Social support is one factor reflecting the barriers and resources as part of the HAPA model: Support is a resource, and the lack of it can be a barrier to adopt or maintain health behaviors [42]. Instrumental, emotional, and informational social support can enable the adoption and continuation of behaviors. Social support can be addressed by means of directly integrating important network partners. For patients in gynecology and obstetrics, this network does not only include the professional at the clinic but also their social support providers such as the spouse or partner, key family members, friends, or the attending midwife who might not be employed with the hospital $[9,20]$. Therefore, a dyadic perspective focusing on both the patient and their social support providers should be taken. For healthcare professionals, an intervention that uses a structured and applicable approach to enhance communication might help them to communicate effectively under a heavy workload. On the one hand, negative effects of impaired physician well-being on communication might be avoided; on the other hand, it is possible that communication becomes less challenging, which relieves stress. This has been shown in the context of nursing homes [44]. We therefore aim to include stress management in the HAPA model for healthcare professionals as a training-related outcome. Multiple studies explain the usefulness of the HAPA model to describe and promote behavior and behavior change (e.g., [45] including compliance [42], hand hygiene $[46,47]$ and vaccination $[48])$.

\section{Research questions and hypotheses}

The interventions in this study will integrate the HAPA model and SACCIA-inspired communication competencies into an advanced training delivered face-to-face in groups of clinical staff, patients and their social support

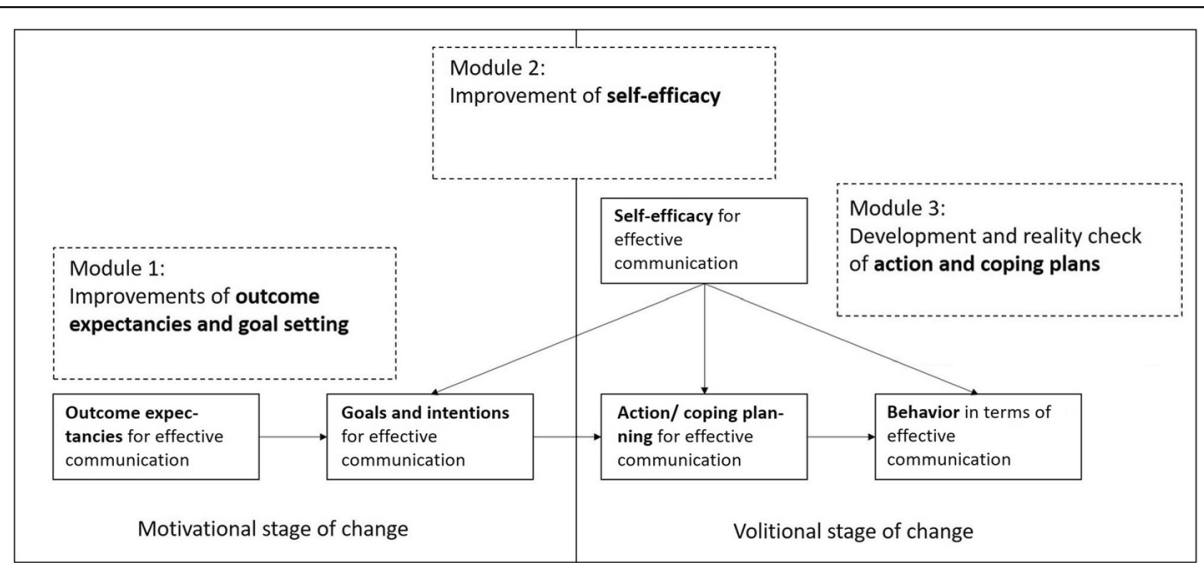

Fig. 1 Components of the HAPA model and planned training modules for improving communication competences and adopting the behavior "effective communication" 
providers. In addition to this, a state-of-the art intervention will make use of digital options by translating the training material into an app $[39,40]$. Previous research has shown that patient coaching can be an intervention to improve communication [49-51], and professionals can also significantly benefit $[52,53]$.

The research questions of this project are the following: what is the effect of a communication training delivered face-to-face and via a digital app on effective communication behaviors? To what extent can patient and healthcare provider satisfaction be improved and pAEs be reduced by improving effective communication behaviors? "Effective communication" is defined and operationalized in this project within the "SACCIA" framework [10, 17]. Beside these main outcomes, personal (e.g., perceived stress, coping) and training-related outcomes (e.g., goal intentions, action planning) will be assessed (see Table 1).

This will be scientifically evaluated using a three-phase study, in which phases are built sequentially on each other and described in detail in the method section: Phase 1, implementation phase (including needs assessment, retrospective cohort study of pAEs) and pre-experimental study with a group and pre-/post-test testing the effect of a training for professionals; Phase 2, quasi-experimental efficacy study with a randomized controlled trial study design (RCT) testing the effect of a training addressing patients and their social support providers; Phase 3, implementation of the app, aimed at staff, patients, and their social support providers, which will test the effect in a case-control study. Efficacy indicators are outlined in Table 1 .

The hypotheses are the following: for Phase 1, it is expected that as a result of the training (1.) the communication competences of healthcare providers will measurably improve. As a result, (2.) healthcare providers will be more satisfied (3.) and the number and severity of pAEs should be significantly reduced for short and medium term (i.e. over the period of the intervention study and beyond). In Phase 2 , it is expected that patients and their social support providers in the intervention group will develop significantly
(4.) higher competences in communication with staff as well as (5.) higher satisfaction after the intervention compared to patients and their social support providers in the control group. It is also expected that (6.) the number and severity of pAEs in the intervention group will be significantly reduced compared to the number and severity of pAEs in the control group. For Phase 3, we hypothesize that the intervention group using the app compared to the intervention group without the app will show (7.) higher patient and healthcare provider communication competences and (8.) satisfaction as well as (9.) a significant reduction in the number and severity of pAEs. The effects of the training on communication competences may be (10.) mediated by trainingrelated and personal outcomes and moderated by organizational factors (11.). All interventions in all phases will improve organizational outcomes if communication competences are improved successfully. Thus, the hypotheses will be tested in this project.

There are three aspects that make this project particularly unique. At first, previous studies have not combined the underlying theories of communication and HAPA, and tailored the intervention to the healthcare context. Secondly, the utilization of a digital app is expected to increase participation and training effectiveness. Thirdly, the project addresses healthcare providers, patients and their social support providers, regarding all people involved in developing effective communication and public health.

\section{Methods/design}

The project will apply a step-wise study design with three study phases in two level one perinatal maternity clinics: Implementation phase and pre-experimental study (Phase 1), a quasi-experimental efficacy study (Phase 2), and a case control study (Phase 3; Fig. 2).

For the study flow of enrollment and interventions for each phase, see the Appendix. All study participants are professionals, patients and social support providers in two participating gynecology and obstetrics clinics,

Table 1 Overview of the addressed concepts and hypotheses (numbers in brackets represent the hypotheses as described in text below)

\begin{tabular}{llll}
\hline & Phase 1 & Phase 2 & Phase 3 \\
\hline Communication competences (1., 4., 7.) & $\uparrow$ & $\uparrow$ & $\downarrow$ \\
Preventable adverse events (pAEs) (3., 6., 9.) & $\downarrow$ & $\uparrow$ & $\uparrow$ \\
Healthcare provider satisfaction (2., 8.) & $\uparrow$ & $\uparrow$ & $\uparrow$ \\
Patient satisfaction (5., 8.) & $\uparrow$ & $\uparrow$ \\
$\begin{array}{l}\text { Training-related outcomes (outcome expectancies, } \\
\text { goals and intention, action planning, coping planning, } \\
\text { behavior, self-efficacy) (10.) }\end{array}$ & $\uparrow$ \\
$\begin{array}{l}\text { Personal outcomes (stress, coping, subjective } \\
\text { safety culture) (10.) }\end{array}$ & $\uparrow$ \\
$\begin{array}{l}\text { Organizational outcomes (adherence to safety } \\
\text { culture) (11.) }\end{array}$ & $\uparrow$ & $\uparrow$ \\
\hline
\end{tabular}

$\overline{\text { Note: }}{ }^{1}$ As described in the HAPA model; $\downarrow=$ Hypotheses that criteria decreases due to the training; $\uparrow=$ Hypotheses that criteria increase; $-=$ no evaluation planned 


\begin{tabular}{|c|c|c|}
\hline $\begin{array}{l}\text { Implementation phase and pre- } \\
\text { experimental study } \\
\text { (phase 1) }\end{array}$ & $\begin{array}{l}\text { Quasi-experimental } \\
\text { efficacy study } \\
\text { (phase 2) }\end{array}$ & $\begin{array}{l}\text { Case-control study } \\
\text { (phase 3) }\end{array}$ \\
\hline $\begin{array}{l}\text { Exploration of the field } \\
\quad \text { Retrospective cohort study (stage A) } \\
\text { Monitoring protocols (observations) } \\
\text { (pAEs, costs) } \\
\text { Implementation phase with needs } \\
\text { assessment } \\
\quad \text { Questionnaires (stage C) } \\
\text { Observations, interviews and focus } \\
\text { groups (stage D) } \\
\text { Preparation and implementation (stage B and } \\
\text { E) of training to promote core competences } \\
>\quad \text { Pre-experimental study (professionals) }\end{array}$ & $\begin{array}{l}\text { Training to promote core competences } \\
\text { - Randomized controlled trial with quasi- } \\
\text { randomization }\end{array}$ & $\begin{array}{l}\text { Implementation stage } \\
\text { - Interviews and focus groups } \\
\text { Feasibility study of a process-supporting } \\
\text { digital intervention (app) } \\
\text { - Case-control study with historical control } \\
\text { groups from phase } 2 \\
\\
\text { Dissemination of the results } \\
\text { - Development of a white paper with } \\
\text { recommendations for practice }\end{array}$ \\
\hline $\begin{array}{l}\text { Target group: Professionals in clinic } \\
\text { (Physicians/ doctors, nursing staff, training } \\
\text { assistants, psychologists, midwives) }\end{array}$ & $\begin{array}{l}\text { Target group: Expectant mothers/ patients } \\
\text { and their accompanying persons (spouses/ } \\
\text { partners, relatives, close friends) }\end{array}$ & $\begin{array}{l}\text { Target group: Professionals in clinics and } \\
\text { expectant mothers/ their accompanying } \\
\text { persons }\end{array}$ \\
\hline $\begin{array}{l}\text { Target criteria: } \\
\text { Primary: communication competences, pAEs } \\
\text { Secondary: training-related outcomes }\end{array}$ & $\begin{array}{l}\text { Target criteria: } \\
\text { Primary: communication competences, pAEs } \\
\text { Secondary: training-related outcomes }\end{array}$ & $\begin{array}{l}\text { Target criteria: } \\
\text { Primary: communication competences, pAEs } \\
\text { Secondary: perceived social support, usability }\end{array}$ \\
\hline
\end{tabular}

Fig. 2 Study flow with project phases and stages, study participants and outcome (Study Flowcharts for all three Phases are in the Appendix). Note. The phases consist of different stages (see Table 3). Stages A to C (see Table 3) will be addressed in Phase 1. Stages D and E will be addressed in Phase 1 and 3

therefore, they receive the regular treatment as patients in terms of healthcare or as staff with human resource (HR) management. Table 2 provides a summary of outcome variables across the study phases.

\section{Phase 1: implementation phase and pre-experimental study Overview of research questions and methods}

For Phase 1, we conduct a needs assessment with regard to overall patient safety, based on the approach proposed by van Sluisveld et al., which aimed to improve the safety of patient transfers in intensive care units [63]. In the current project, this approach will be applied to gynecology and obstetrics clinics with their staff, patients (expecting mothers/women who are about to deliver or who gave birth recently), and social support providers (e.g., spouse/partner, relatives, close friends, Fig. 2). The approach differentiates into stages A to E (see Table 3), which will be conducted accordingly in the current study.

Observations for the ethnographic analyses will be recorded using a standardized observation protocol [30]. The qualitative data will be analyzed in terms of inductive content analysis and will be used to develop the training. The details of this approach are described in Sluisveld et al. (2013) [63]. Focus groups and interviews will be conducted with partially standardized guidelines with at least one person from each occupational group in order to gain an impression of potential resources and barriers as comprehensive as possible (as found by previous research, e.g. [6]) for the implementation of the intervention [22]. Immigration background will be considered during data collection and testing as well as during app development (i.e. it will be ensured that patients and social support providers with an immigration background will also be included in the development as cultural background was found to influence communication behaviors $[9,61,62,64])$.

This approach will lead to a comprehensive understanding of factors that facilitate and inhibit effective communication and pAE's. Additionally, it will identify possibilities and potential benefits for the implementation of the intervention in the field, e.g., how communication competences can be integrated into clinical practice beyond the training. Possible options include daily communication logs, regular e-mails with tips on practical application etc.

The results will be used to develop the training for professionals (physicians, nursing staff, training assistants, psychologists, midwives), which will be implemented in Stage E of Phase 1 in this project (pre- 
Table 2 Overview over the outcome variables and covariates considered in the different study phases

\begin{tabular}{|c|c|c|c|c|c|c|}
\hline & \multicolumn{2}{|c|}{ Phase 1} & \multicolumn{2}{|c|}{ Phase 2} & \multicolumn{2}{|c|}{ Phase 3} \\
\hline & $\mathrm{T} 1$ & $\mathrm{~T} 2$ & $\mathrm{~T} 1$ & $\mathrm{~T} 2$ & $\mathrm{~T} 1$ & $\mathrm{~T} 2$ \\
\hline \multicolumn{7}{|l|}{ Primary outcomes } \\
\hline Communication competences $^{1}$ & $x$ & $x$ & $x$ & $x$ & $x$ & $x$ \\
\hline Preventable adverse events $(\mathrm{pAEs})^{2}$ & $x$ & $x$ & $x$ & $x$ & $x$ & $x$ \\
\hline \multicolumn{7}{|l|}{ Secondary outcomes } \\
\hline Healthcare provider satisfaction ${ }^{3}$ & $x$ & $x$ & $x$ & $x$ & $x$ & $x$ \\
\hline $\begin{array}{l}\text { Patient/treatment satisfaction }{ }^{3} \\
\text { (patients/social support providers) }\end{array}$ & & & $x$ & $x$ & $x$ & $x$ \\
\hline Training-related outcomes ${ }^{4}$ & $x$ & $x$ & $x$ & $x$ & $x$ & $x$ \\
\hline Personal outcomes ${ }^{5}$ & $x$ & $x$ & $x$ & $x$ & $x$ & $x$ \\
\hline \multicolumn{7}{|l|}{ Organizational outcomes } \\
\hline Adherence safety culture ${ }^{6}$ & $x$ & $x$ & $x$ & $x$ & $x$ & $x$ \\
\hline Subjective safety culture ${ }^{7}$ & & & $x$ & $x$ & $x$ & $x$ \\
\hline \multicolumn{7}{|l|}{ Covariates } \\
\hline $\begin{array}{l}\text { Socio-demographic variables } \\
\text { including migration status }\end{array}$ & $x$ & & $x$ & & $x$ & \\
\hline
\end{tabular}

Note: Examples for the measurements are:

${ }^{1}$ Self-developed questionnaire

2 Operationalized via trigger events (such as unavailable staff, equipment failure, readmissions, length of stay, communication error) as defined by [54, 55]

${ }^{3}$ Nurses' job satisfaction scale [56]

${ }^{4}$ HAPA questionnaire including outcome expectancies, goals and intentions/motivation, action planning and coping planning, behavior, self-efficacy, perceived stress see $[25,42,45-48]$

${ }^{5}$ Emotional exhaustion, depersonalization, perceived social support $[4,57]$

${ }^{6}$ The Hygiene Inventory - 23 items (HI-23) [58]

${ }^{7}$ Measures equivalent to the ones used in $[59,60]$

${ }^{8}$ Age, gender, education, professional experience, depressive symptoms, anxiety and migration [61, 62]

experimental study; see Fig. 4 in the Appendix). The results will also be used to develop the training for patients and their social support providers in a quasi-experimental efficacy study in Phase 2 (see Fig. 5 in the Appendix). An equivalent procedure applying and testing a training program was successfully performed in a recent study [12]. However, only staff members were addressed and no communication competences or HAPA variables were targeted. In the current study, due to theoretical, ethical and methodological reasons, all individuals should get the benefit of the training. All professionals will be assigned to the intervention group and the evaluation will be done by a pre/post comparison.

\section{Translation of the HAPA model into practice - development of the training}

The design of the communication training will be informed by theory and previous empirically tested trainings. Exhibiting effective communication will be the desired behavioral outcome as specified in the HAPA model (Fig. 1). Performance modeling, performance desensitization (stemming from work on fears and anxiety disorders), performance exposure and self-instructed performance are all good methods for designing treatments that target enactive mastery experience [37, 38], or maintain the desired behavior in the HAPA model. An example would be to instruct persons to monitor and record how many times a day they have performed effective communication in face of time pressure and to track this on paper (Phase 1 and 2), or in the app (Phase 3). All of the above elements will be integrated into the trainings for professionals (in Phase 1, see Table 4) and for patients and their social support providers (in Phase 2, see Table 5).

Training for professionals will take place during work hours and will last approximately 4 hours. Training for patients will last approximately 8 hours. The concrete development of the intervention content and procedure, in addition to the above description, is an important step towards employing participatory intervention development within this first study phase. The subsequent publications on the actual intervention contents and procedures will contribute to the current paper and allow for the replication of this study, including the interventions.

\section{Procedure, sample, and data collection}

Training for professionals at the clinics will integrate the communication competences and will be designed based on the HAPA model. A short manual will be provided to support the participants in implementing the lessons they 
Table 3 Implementation phase: Research questions, methods, study participants and target criteria with regards to patient safety

\begin{tabular}{|c|c|c|c|c|}
\hline Stage & Research questions & Methods & Target group/data source & Outcome measures \\
\hline \multirow[t]{2}{*}{ A } & $\begin{array}{l}\text { What is the status of communication } \\
\text { competences? }\end{array}$ & $\begin{array}{l}\text { Questionnaire (self- } \\
\text { developed) }\end{array}$ & Healthcare providers & $\begin{array}{l}\text { Communication competences as } \\
\text { described by the SACCIA framework }\end{array}$ \\
\hline & What is the prevalence of pAEs? & $\begin{array}{l}\text { Routine data } \\
\text { Mixed Methods study, } \\
\text { Analysis of birth protocols } \\
\text { (observations), staff } \\
\text { questionnaire }\end{array}$ & $\begin{array}{l}\text { Anonymous routine data of } \\
\text { the hospital from the last year } \\
\text { (2018), birth protocols and } \\
\text { patient records, subjective } \\
\text { prevalence }\end{array}$ & $\begin{array}{l}\text { Quality indicators: pAEs such as } \\
\text { unavailable staff, equipment failure, } \\
\text { readmissions, length of stay, } \\
\text { communication errors }\end{array}$ \\
\hline B & $\begin{array}{l}\text { What are effective interventions } \\
\text { to improve safety and communication } \\
\text { in everyday hospital life? }\end{array}$ & Scoping review & $\begin{array}{l}\text { Pubmed, Psychlnfo, Cochrane } \\
\text { Database } \\
\text { Web of Science Core } \\
\text { Collection database }^{1}\end{array}$ & $\begin{array}{l}\text { Overview of effective interventions } \\
\text { and effect sizes }\end{array}$ \\
\hline C & $\begin{array}{l}\text { What is the adherence for current } \\
\text { patient safety measures (e.g., hand } \\
\text { hygiene)? }\end{array}$ & Questionnaire, e.g., HI-23 & $\begin{array}{l}\text { All professionals at both } \\
\text { intervention sites }\end{array}$ & $\begin{array}{l}\text { Adherence to patient safety } \\
\text { measures; relationships between } \\
\text { adherence and quality indicators incl. } \\
\text { patients' satisfaction with their } \\
\text { treatment and professionals work } \\
\text { satisfaction }\end{array}$ \\
\hline $\mathrm{D}$ & $\begin{array}{l}\text { What are the resources and barriers } \\
\text { for the implementation of an } \\
\text { intervention in order to optimize } \\
\text { communication in everyday hospital } \\
\text { life? }\end{array}$ & $\begin{array}{l}\text { Ethnographic observation; } \\
\text { Individual semi-structured } \\
\text { and focus group interviews }\end{array}$ & $\begin{array}{l}\text { Physicians, nursing staff, } \\
\text { training assistants, } \\
\text { psychologists, midwives }\end{array}$ & $\begin{array}{l}\text { Resources and barriers classified } \\
\text { according to: (1.) intervention } \\
\text { characteristics; (2.) societal context, } \\
\text { (3.) implementation characteristics, } \\
\text { (4.) institutional characteristics, (5.) } \\
\text { social context, (6.) professional } \\
\text { characteristics, and (7.) patient } \\
\text { characteristics. }\end{array}$ \\
\hline E & $\begin{array}{l}\text { What is an appropriate strategy to } \\
\text { implement effective interventions to } \\
\text { optimize communication? }\end{array}$ & $\begin{array}{l}\text { Intervention mapping with } \\
\text { the method of Bartholomew } \\
\text { and Kok (2011), triangulation } \\
\text { of results from previous } \\
\text { stages }\end{array}$ & $\begin{array}{l}\text { Matching of data from } \\
\text { interviews, focus groups and } \\
\text { questionnaires with evidence } \\
\text { from the literature }\end{array}$ & $\begin{array}{l}\text { Implementation strategy tailored to } \\
\text { the found resources and barriers to } \\
\text { the implementation of effective } \\
\text { interventions to increase patient } \\
\text { safety }\end{array}$ \\
\hline
\end{tabular}

Note: pAEs = preventable adverse events; the content of this table is based on Table 2 in [63]

${ }^{1}$ The literature search for this paper used the following search term combinations:

Communication Training/Intervention AND Resource AND Implementation AND Health Experts

Communication Training/Intervention AND Barrier AND Implementation AND Professionals/Patients

Communication Training/Intervention AND Resource/Barrier AND Outcome Expectancies

We always maintained "Communication, Training, Intervention, Resource, Barrier" as search terms and will refine the larger searches with the following terms:

Intention, plan, behavior, social-cognitive

Table 4 Contents and planned structure of the training for professionals (in Phase 1)

\begin{tabular}{ll}
\hline 1st part & 2nd part \\
\hline $\begin{array}{l}\text { Introduction and warming up; } \\
\text { preview learning goals }\end{array}$ & $\begin{array}{l}\text { Case studies and analyses } \\
\text { with practical exercises } \\
\text { and reflection on expectations }\end{array}$ \\
$\begin{array}{l}\text { and discussion } \\
\text { Training Part 1: }\end{array}$ & $\begin{array}{l}\text { Module 2: } \\
\text { Imtroduction in communication }\end{array}$ \\
$\begin{array}{l}\text { and patient safety } \\
\text { Training Part 2: }\end{array}$ & Training Part 3: \\
$\begin{array}{l}\text { Previous experiences with } \\
\text { communications skills/challenges }\end{array}$ & $\begin{array}{l}\text { Further work on communication } \\
\text { competences }\end{array}$ \\
$\begin{array}{l}\text { Module 1: } \\
\text { Improvements of outcome } \\
\text { expectancies } \\
\text { and goal setting }\end{array}$ & $\begin{array}{l}\text { Module 3: } \\
\text { Development and reality check }\end{array}$ \\
Transfer, reflections and feedback & of action and coping plans \\
& \\
Active break with networking and & Closing meeting with rounding \\
social support &
\end{tabular}

learn into their working practice. Written documentation of the training will also be provided to avoid failure of implementation. The training will be offered to all professionals at both intervention sites. Its effectiveness will be tested in the pre-experimental study, which aims to investigate the association between training participation and the reduction/occurrence of pAEs, to observe the mechanisms that make the training successful with regard to supporting professionals in their work and understanding how patient training can be implemented in Phase 2 .

The study (Stage E of Phase 1) has a one-group, pre-/post-design (see Fig. 4 in Appendix). It includes all professionals (e.g., doctors, nursing staff, midwives/ obstetricians, training assistants, psychologists) at all locations and intends to recruit a total of $N=140$ participants without any participant exclusion criteria. Professionals will be trained in interdisciplinary groups of 10 to 12 participants. Recruitment will take place via the hospitals involving line managers, works 
Table 5 Contents and planned structure of the training for patients and their social support providers (in Phase 2)

\begin{tabular}{|c|c|}
\hline 1st day ${ }^{l}$ & 2nd day \\
\hline $\begin{array}{l}\text { Introduction and warming up; } \\
\text { preview learning goals and } \\
\text { reflection on expectations }\end{array}$ & $\begin{array}{l}\text { Introduction and warming } \\
\text { up }\end{array}$ \\
\hline $\begin{array}{l}\text { Training Part } 1: \text { Introduction in communication } \\
\text { and patient safety }\end{array}$ & $\begin{array}{l}\text { Module 2: Improvement } \\
\text { of self-efficacy }\end{array}$ \\
\hline $\begin{array}{l}\text { Active break for networking } \\
\text { and social support }\end{array}$ & Active morning break \\
\hline $\begin{array}{l}\text { Training Part 2: Previous experiences with } \\
\text { communications skills/challenges }\end{array}$ & $\begin{array}{l}\text { Training Part 3: } \\
\text { Further work on } \\
\text { communication } \\
\text { competences }\end{array}$ \\
\hline $\begin{array}{l}\text { Module 1: Improvements of } \\
\text { outcome expectancies and } \\
\text { goal setting }\end{array}$ & $\begin{array}{l}\text { Active break for networking } \\
\text { and social support }\end{array}$ \\
\hline \multicolumn{2}{|l|}{$\begin{array}{l}\text { Active break for networking } \\
\text { and social support mobilization }\end{array}$} \\
\hline $\begin{array}{l}\text { Case studies and -analyses } \\
\text { with practical exercises and } \\
\text { discussion }\end{array}$ & $\begin{array}{l}\text { Module 3: Development } \\
+ \text { reality-check of } \\
\text { action and coping plans }\end{array}$ \\
\hline Transfer, reflections and feedback & $\begin{array}{l}\text { Closing meeting with } \\
\text { rounding up further } \\
\text { transfer exercise }\end{array}$ \\
\hline
\end{tabular}

Note: ${ }^{1}$ Patients and their social support providers receive the training during two mornings. If participants are interested in an advanced training, another session will be provided

councils, quality management departments, and HR departments. They will be involved to ensure adequate participant enrollment to reach target sample size. Participants will be included in the analysis only if they provide informed consent, which will be collected by project managers working at the hospitals. Data will be analyzed according to intention to treat. If study participants withdraw their consent to be contacted for follow-up measurements at any point, their contact details will be removed from the database. If they indicate that they do not want their data included in the analyses, their data will also be removed. Otherwise, they will be considered as study dropout. All target criteria are shown in Table 2.

\section{Statistical analyses}

Training effects will be tested by evaluating differences between the measurement times using linear and general mixed models. Baseline values of the first measurement time point will be considered as covariates. Clinics are modeled as fixed effect. Key demographic variables such as age, gender and occupation will be used to calculate selectivity in dropout rates. Missing data per measurement point, but also over time, will be treated by advanced methods to handle missing data such as the full information maximum likelihood method (FIML; this will be the same in all other phases, too).
Phase 2: quasi-experimental efficacy study Aim/overview of research questions and methods

In Phase 2 (see Fig. 2 and Fig. 5 in Appendix), the effectiveness of the communication competences intervention for the target group of patients and their social support providers will be tested using the gold standard, i.e. a randomized control trial (RCT). This intervention will be based on all stages of Phase 1 of this project, and thus will be developed in a participatory approach with patients and professionals working in the clinics [63]. The intervention will enable patients and social support providers to gain knowledge about the prevalence of pAEs and communication problems as well as expectations of action results. Moreover, it will allow participants to practice communication competences and develop their selfefficacy. Furthermore, the intervention will utilize the provided theoretical input in order to integrate theory into everyday hospital life by means of action and coping plans. To implement the acquired competences as effectively as possible, the following three components will be addressed in the intervention [65]:

1. the motivation or intention to communicate effectively and confidently with each other,

2. the knowledge of what is crucial for effective communication,

3. the ability to communicate effectively.

The intervention is based on the HAPA model as a social-cognitive model for behavioral change [25] and communication competences (see description of the training above in Phase 1). Participants will be trained in groups by specialized instructors over the course of one and a half days in facilities of the participating clinics (see Table 5, and Fig. 5 in Appendix).

\section{Procedure}

In each hospital, four professionals will be taught in a trainthe-trainer seminar to train patients and their social support providers based on the short manual developed to teach communication competences. Recruitment will take place via the doctors, nurses and midwives in the hospitals (Fig. 5 in Appendix). The quality management departments will be involved to ensure adequate enrollment in order to reach the target sample size of $\mathrm{N}=423$ participants. Informed consent will be collected by on-site project managers. When an expectant mother is admitted to the clinic and agrees to participate in the study, she will be randomly assigned to a training group (IG) or a control group (CG). If she is accompanied by a partner, relative, or close friend, they will be assigned to the same group. All patients and social support providers randomly assigned to the intervention group will receive the same training content over the course of this 
study. In contrast, the control group will receive the hospital care-as-usual (see Fig. 5 in Appendix).

Randomization will be done per site and day (block randomization). The central project coordinator will generate the allocation sequence. Depending on this sequence, all patients admitted to the hospital on that day will be allocated to either the IG or to the CG. Patients and staff will not be informed beforehand on which days allocation to the IG or the CG takes place to prevent biases. Instead, the on-site project manager at each hospital will receive a sealed envelope each day containing this information, enabling them to inform other staff involved as well as enroll and assign participants to the CG or IG treatment. This process allows trial participants, general care providers, outcome assessors and data analysts to remain blinded throughout the allocation sequence. Trial participants and general care providers will be unblinded in case they ask for more information about the training. Revealing a participant's allocated intervention during the trial can be performed after completion of the IG treatment to disclose the content of the intervention. A flyer will be provided containing this information, which will be also used after the study to disseminate findings and tools. Inclusion and exclusion criteria are outlined in Table 6.

According to a power analysis, a sample of $N=352$ is necessary (alpha error $=0.05$, power $=80 \%$, to be analyzed IG analysis: $N=176$; CG analysis: $N=176$ ) in order to detect an effect size of $d=0.3$. With an assumed drop-out rate of $20 \%, N=423$ participants (IG recruited: $N=212$; CG recruited: $N=211$ ) have to be recruited in the study. The pAEs will be collected on an individual basis (anonymized) and coded according to the communication competences (see Fig. 5 in Appendix).

\section{Statistical analyses}

The target criteria (see Tables 1 and 2) will be evaluated statistically and clinically, as in Phase 1, with linear and general mixed models and with superiority trial tests to investigate whether the intervention is better than the standard care. As expecting mothers and their social support providers participate in the intervention, dyadic data will be assessed and analyzed. Additional analyses will test whether subgroups of patients with psychological risk factors (e.g., depressive symptoms, anxiety) and low motivation benefit from the intervention to the same extent as study participants without such risk factors. Furthermore, adjusted analyses will be performed in terms of ANCOVAs considering factors related to social inequality, such as education, anxiety, and immigration status (see also Table 2).
Table 6 Summary of the inclusion and exclusion criteria

\begin{tabular}{|c|c|}
\hline Inclusion criteria & Exclusion criteria \\
\hline $\begin{array}{l}\text { Expectant mother or patient in } \\
\text { gynecology and obstetrics or } \\
\text { social support providers } \\
\text { (spouse/partner, relative, } \\
\text { close friend) to be recipient } \\
\text { of the training } \\
\text { Professional in a gynecology } \\
\text { and obstetrics hospital to be } \\
\text { trainer of the patients and the } \\
\text { social support providers }\end{array}$ & $\begin{array}{l}\text { Not proficient in the } \\
\text { German language and/or does not have the } \\
\text { capability of writing } \\
\text { Severe cognitive deficits } \\
\text { (unable to read/write/ } \\
\text { answer questions) and } \\
\text { impairments due to } \\
\text { diagnosed brain injuries, } \\
\text { neurological disorders, etc. } \\
\text { Insufficient corrected } \\
\text { eyesight (patients must be } \\
\text { able to read on the cell } \\
\text { phone) } \\
\text { Participation in another } \\
\text { research study or } \\
\text { intervention trial conducted } \\
\text { in the clinic }\end{array}$ \\
\hline Aged 18 years and above & Younger than 18 years \\
\hline Healthy volunteers & High risk, emergency case \\
\hline $\begin{array}{l}\text { Declaration of consent } \\
\text { for participation in the study }\end{array}$ & $\begin{array}{l}\text { Withdraw of consent for } \\
\text { participation in the study } \\
\text { at any point in time }\end{array}$ \\
\hline
\end{tabular}

\section{Phase 3: implementation of the app and case-control study} Functions of the app

A digital app will be developed to help users communicate well. The app will be developed in a participatory and theory-driven way from all findings and conclusions obtained in Phases 1 and 2 (Fig. 2) [66]. Stages D and E of Phase 1 will be repeated with professionals, expecting mothers/patients, and social support providers to update the evidence and answer questions that may have arisen during Phase 2 . The aim of Phase 3 is to determine exactly how the app can support communication between professionals, patients, and their social support providers in their daily work/hospital experience and thereby lead to a reduction in pAEs. As app users will have completed the face-toface training, they can use the app at their convenience to monitor their behavior and experiences (see Fig. 3) and deepen their skills and knowledge. To achieve this aim, there will be two functions of the app.

Firstly, the app will be designed to provide guidance on how to cope with specific (future) communication problems including communication initiated by a) the patient, b) the professional and c) between professionals. The following scenarios illustrate how the app may improve communication. Regarding a), if a woman prepares for a conversation with a professional in a labor ward, she may worry about how to express the wish for peridural anesthesia or more anesthesia if the pain escalates (cf. [21]). The app explains/ provides suggestions to her (and her social support providers) how to communicate this wish in a clear and constructive way [43, 51] (Fig. 3). This may enable shared decision making in terms of understanding risks and disadvantages. Furthermore, she is supported to ask the right questions or maybe even audio record her questions and the 


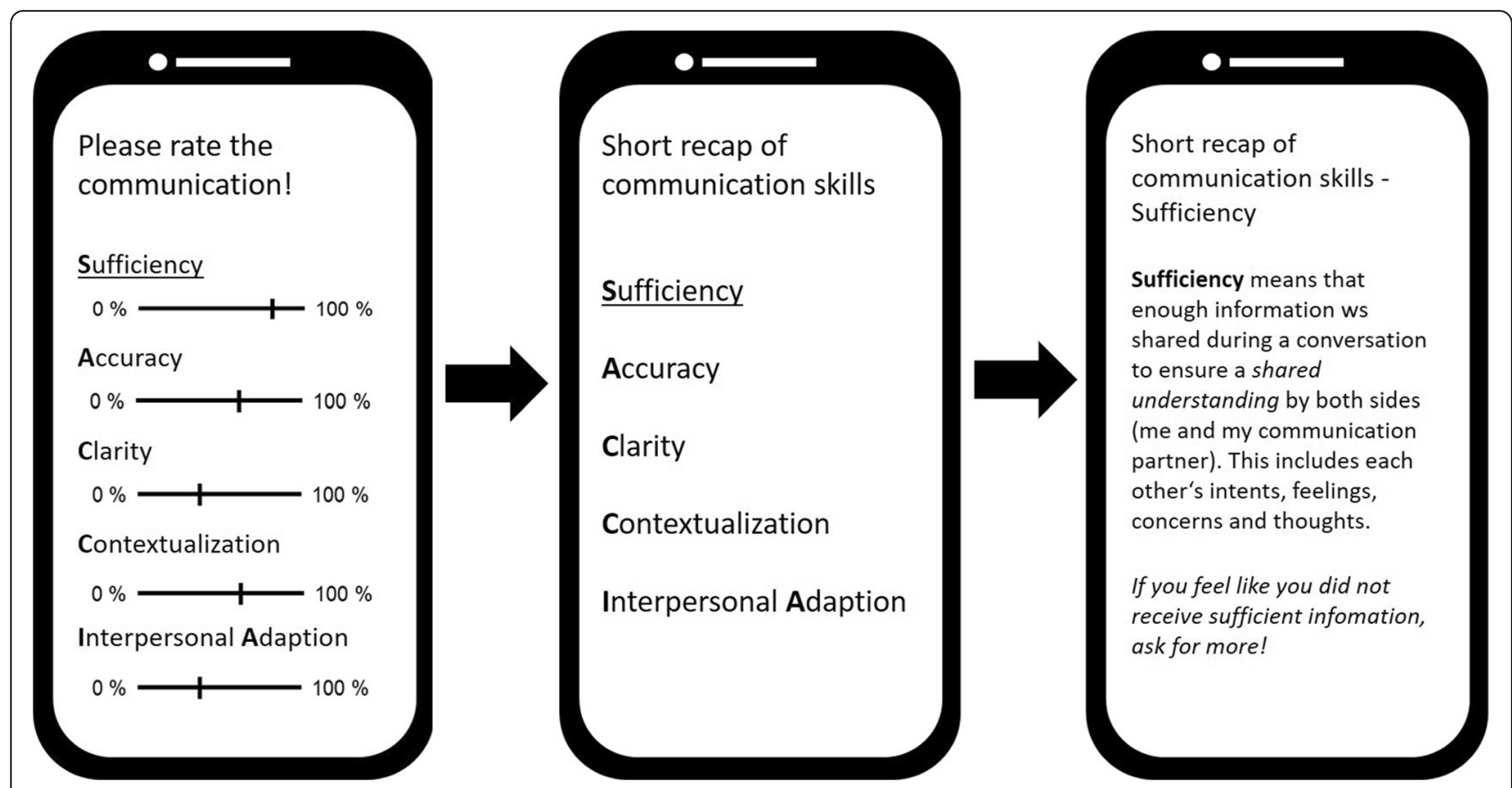

Fig. 3 Example of the monitoring and guidance functions of the app

answers from professionals, as it has been done in previous research [49]. Regarding b), a doctor may be unsure how to handle the expectant mother's fear of childbirth and postpartum posttraumatic stress disorder (cf. [67]). Typical problems include sharing bad news and dealing with difficult emotions $[24,68,69]$. The app would help the doctor to communicate accurate information in a way that still addresses the fear that may come along with bad news. This may prevent complications due to insufficient information. Professionals will be asked to analyze and solve scenarios that involve both patients and their social support providers. The app will then explain the communication competences again and give concrete suggestions how to use them for solving the case. Depending on demands, the app will give suggestions such as "Speak slowly", "Try not to use acronyms or abbreviations", "Try to refrain from using scientific terms", "Make use of visualizations", "Be sensitive to verbal and non-verbal cues that may indicate lack of understanding", "Stress the most important aspects that the patient must keep in mind", and "Make use of the teach-back method" [19]. Regarding c), one team member of the delivery ward knows that a high-risk patient in labor needs prophylactic negative-pressure wound therapy (NPWT) after cesarean delivery, but they do not know how to communicate this to colleagues under time pressure [20]. The app helps to overcome time pressure by providing a message on the display for the colleagues which can be copied to a piece of paper, and thus support communication [70]. All of the above cases will be provided to colleagues, who will be asked to analyze and solve them. Communication competences will be explained with regard to communication between colleagues. Depending on demands, specific suggestions such as communication tools (daily goal sheet, bedside whiteboard, or door communication card), trust building, mindfulness, and reflective exercises will be given [71].

Secondly, the app will assist in monitoring typical or recent communication with focus on (1.) one's own role, (2.) the role of the communication partner and (3.) resonance (a feeling of mutual understanding), thus supporting the development of general communication competences. These aspects will be evaluated with regard to the communication competences (see Tables 1 and 2).

Learning from the communication of all participants is ensured by collecting dyadic self-reported data and the partners reported data. Concretely, target-group specific tasks that train general communication competences seldom aid to overcoming specific obstacles, so reminders of resources and application/transfer options will be provided in the app, too.

\section{Procedure, sample and data collection}

Patients will be recruited via doctors and midwives in the hospitals; recruitment of staff and collection of informed consent of both patients and staff will be conducted by the on-site project managers. Quality management departments will be involved to ensure adequate participant enrollment to reach the target sample size. The target criteria of the patient sample will be evaluated statistically and clinically as in Phase 1 and 2 (see Table 2). Group differences will be tested with linear and general mixed models and with superiority 
trial tests that investigate whether the intervention is helping more than the standard care in Phase 2.

\section{Statistical analyses}

To test the effectiveness of the digital app, a case-control study will be performed (see Fig. 6 in Appendix). Cases are newly recruited individuals that fulfil the inclusion criteria outlined in Table 6. Comparators/controls are the participants in one of the two intervention arms of the previously conducted RCT study in Phase 2 (i.e. patients; historical control groups; No-Treatment CG analysis: $N=$ 176; No-Treatment CG recruited: $N=212$; Previously Treated/Active CG analysis: $N=176$ (called IG1 in Fig. 6 in Appendix); Previously Treated/Active CG recruited: $N=$ 212, see in section Phase 2). $N=176$ participants need to be analyzed for the intervention group (IG2 analysis). Assuming a drop-out of $20 \%, N=212$ participants have to be recruited for the intervention group (IG2 recruited) in Phase 3 (see Fig. 6 in Appendix). The intervention will also be provided to the professionals in the clinic. Adoption and acceptance of the intervention will be evaluated in all groups by means of observational data and self-report. Target criteria are specified in Tables 1 and 2.

At the end of Phase 3, the results from all three phases will be disseminated using a white paper with recommendations for practice. Further plans to communicate trial results to participants, healthcare professionals, the public, and other relevant groups via publication, presentations and press releases will be developed using a participatory approach, with the restriction that anonymity is ensured at all times.

\section{Discussion}

This project investigates interpersonal communication based on communication competences and the Health Action Process Approach (HAPA) to better understand where and how problems may occur and how to overcome these problems with interventions in everyday clinical life. Currently, there is no study that has done so in everyday clinical practice and has demonstrated the effectiveness of corresponding interventions based on the two theories as theoretical backdrop for designing the intervention.

The overall aim of the project is to support communication based on the communication competences model and the HAPA, and to overcome difficulties in everyday hospital life. The project is characterized by three innovative aspects. The first innovative aspect is the theoretical background and its application to maternity clinics. The communication competences model has been specifically designed to address communication in the healthcare context, whereas the HAPA model has been shown to bridge the gap between intention and behavior [25]. The combination of both HAPA and communication competences will aid in the design of an intervention specifically tailored to the healthcare context, which increases its potential effectiveness.

The second innovation of this project lies in its digital focus, and thus, a focus on innovation policy. The question is, to what extent can digital support of interpersonal communication actually support effective communication and which evidence-based recommendations can be given? Although there is some evidence, which we have reviewed in the beginning of this paper, this new project has a clear innovative potential to set the stage for future research in public health and prevention.

The third innovative aspect of this project lies in its systematic empirical investigation of including professionals, patients and their social support providers as active partners for patient safety. This adds to the value of this project by assessing dyadic data and is currently also regarded by the $\mathrm{WHO}$ as a central issue in patient safety [72].

Despite the need for developing healthcare professionals' and patients' communication skills, (ongoing) face-to-face training is rather time-consuming and may not be achievable given the overall need for increasing hospital efficiency [73]. Digital communication training offers a solution to this dilemma as it reduces costs and organization resources. Moreover, users can participate in the training according to their own schedules, thus potentially increasing their motivation and the training's effectiveness, but only if the digital trainings are sufficiently implemented and monitored [74].

Two studies included in a previous review evaluated the effectiveness of training interventions to improve communication [9]. The training package targeting communication skills for doctors was not associated with higher satisfaction with work scores recorded by women, although they reported high satisfaction with training workshops [75]. While Crofts et al. reported that improvements in all their test variables in the three clinical scenarios were statistically significant after the training, this was based on a pre- and postintervention analysis with no comparison groups [76]. Perceptions of safety and communication significantly improved after training with patient-actors, compared to training using mannequins for postpartum hemorrhage scenarios, but it is unclear why no statistically significant improvements were found. Furthermore, the authors revealed no benefits of additional teamwork training on patient-actor perceptions of care related to safety, communication, and respect [76]. Due to the innovative aspects outlined above, our own evaluation is expected to outperform these previous effects in order to support communication. This study will also provide valuable information on the effectiveness, useracceptability, and feasibility of the intervention. It addresses the need to investigate new approaches to improve communication, which can relieve health systems from the growing demands caused by challenges with communication around the world and in all areas of medicine and public health. 


\section{Appendix}
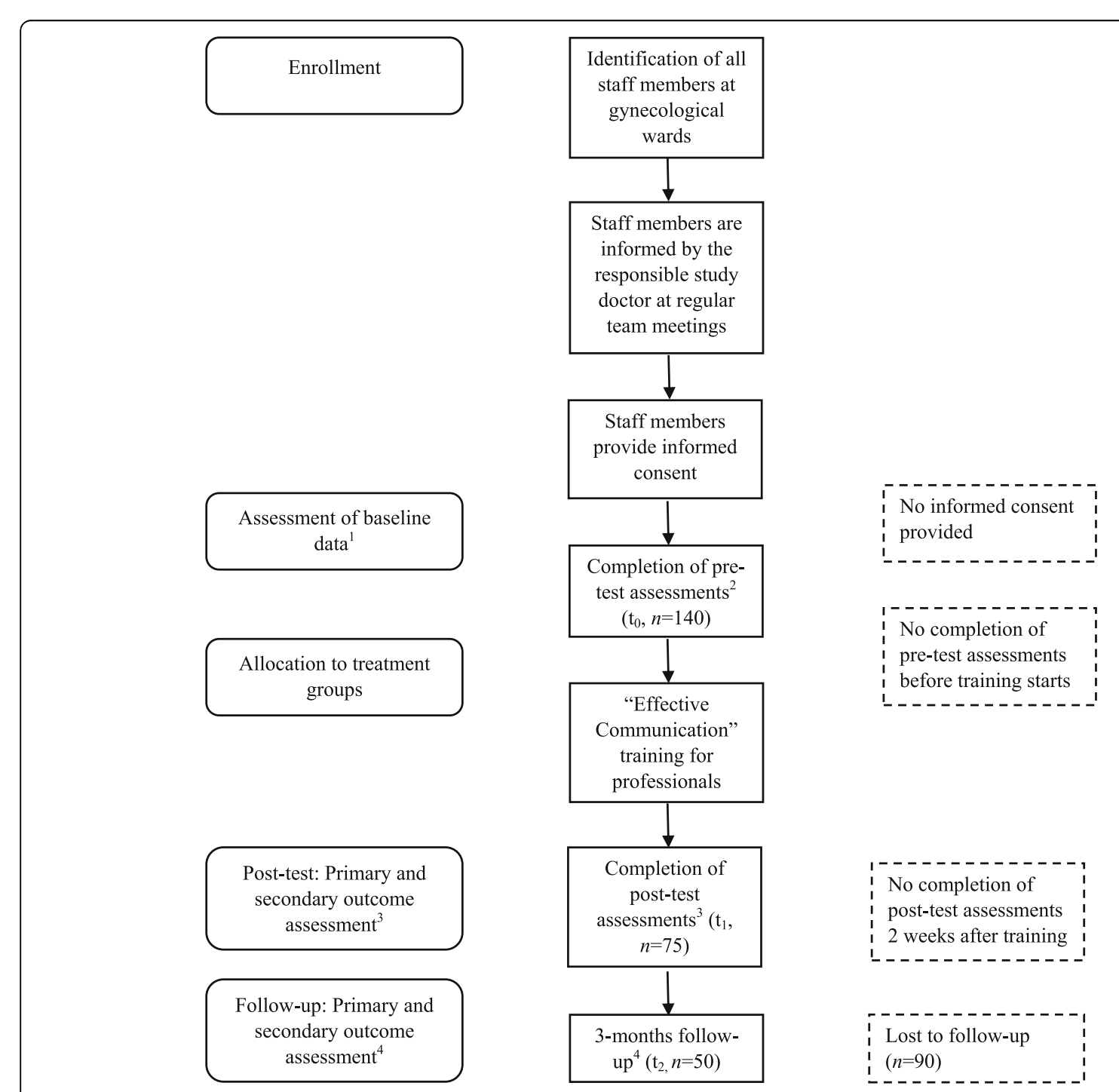

Fig. 4 Trial design for Phase 1. Step 1: Participants (clinical staff members) are initially identified, informed and invited to take part in the training. Step 2: Participants give informed consent while baseline variables that can be measured independently are assessed. All participants in this phase receive the training so that there is no allocation to either treatment or control group but only to similar treatment groups. Step 3: Pre-tests ${ }^{2}$. Step 4: Participants complete the communication training. Step 5: Post-tests ${ }^{3}$. Step 6: Follow-up after 3 months. Note: ${ }^{1}$ Baseline data includes baseline assessments of pAE prevalence and costs, adherence safety culture and job description. ${ }^{2}$ Pre-test assessment includes demographic data, competences, training-related outcomes and work satisfaction. ${ }^{3}$ Post-test assessments include competences and training-related outcomes. ${ }^{4}$ At three months post-intervention, job stress and satisfaction, competences, behavior change as training-related outcomes and adherence safety culture will be assessed. 


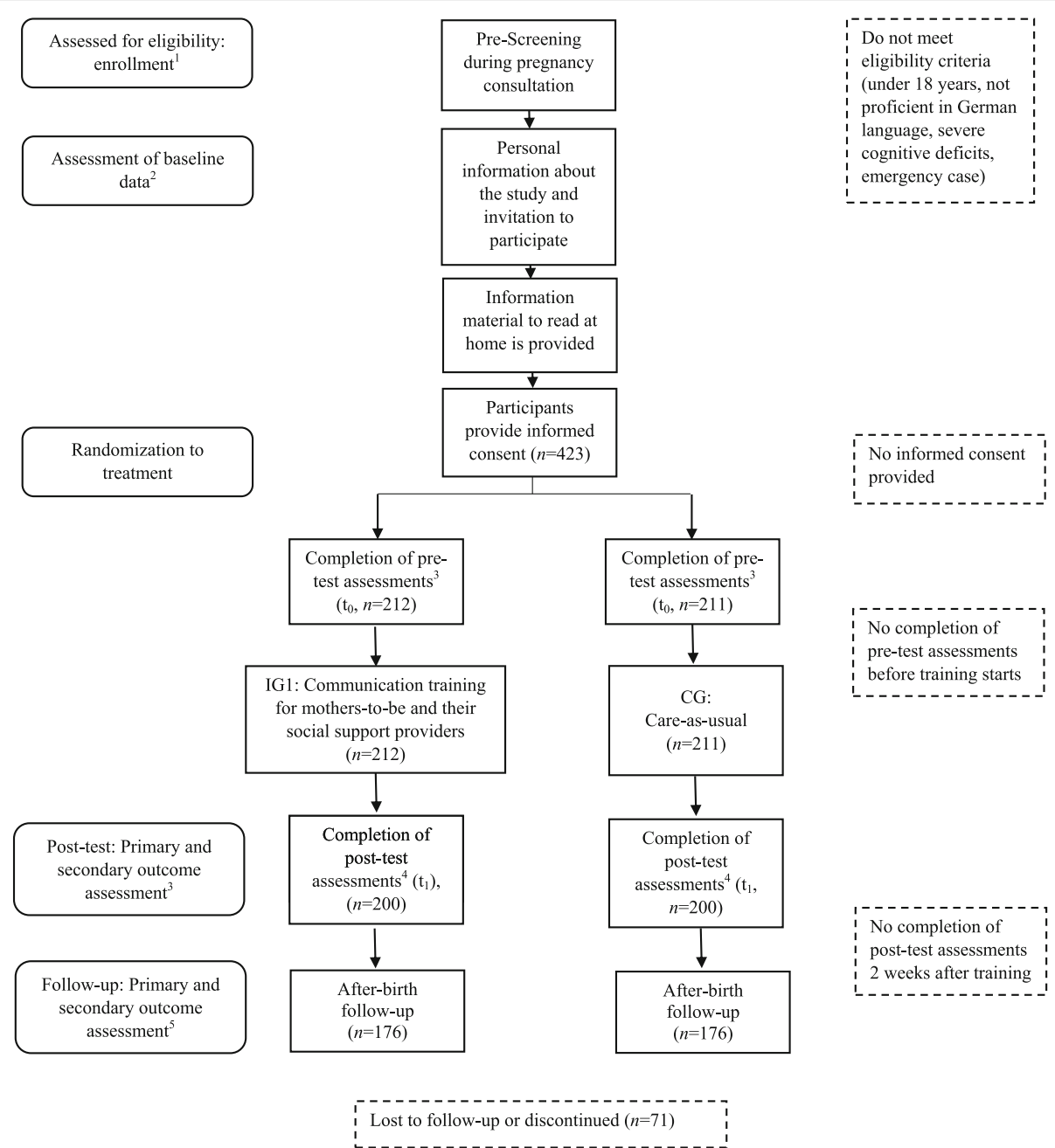

Fig. 5 Trial design for Phase 2. Step 1: Participants (mothers-to-be/patients and their social support providers) are initially identified and screened for eligibility. Step 2: If eligible, participants are invited to take part in the study, give informed consent and are allocated to either the intervention group (IG, Communication training) or the control group (CG). Step 3: Pre-tests. Step 4: Participants in the intervention group complete the communication training. Step 5: Post-tests. Step 6: pAEs are assessed after the patient gave birth. Note: ${ }^{1}$ For inclusion and exclusion criteria, see Table $6 .{ }^{2}$ Baseline data includes baseline assessments of pAE prevalence and costs. ${ }^{3}$ Pre-test assessment includes demographic data, perceived social support, competences, training-related outcomes, subjective safety culture and treatment satisfaction. ${ }^{4}$ Post-test assessments include perceived social support, competences and training-related outcomes. ${ }^{5}$ At three months post-intervention, perceived social support, competences, behavior change as training-related outcome, subjective safety culture and treatment satisfaction will be assessed 


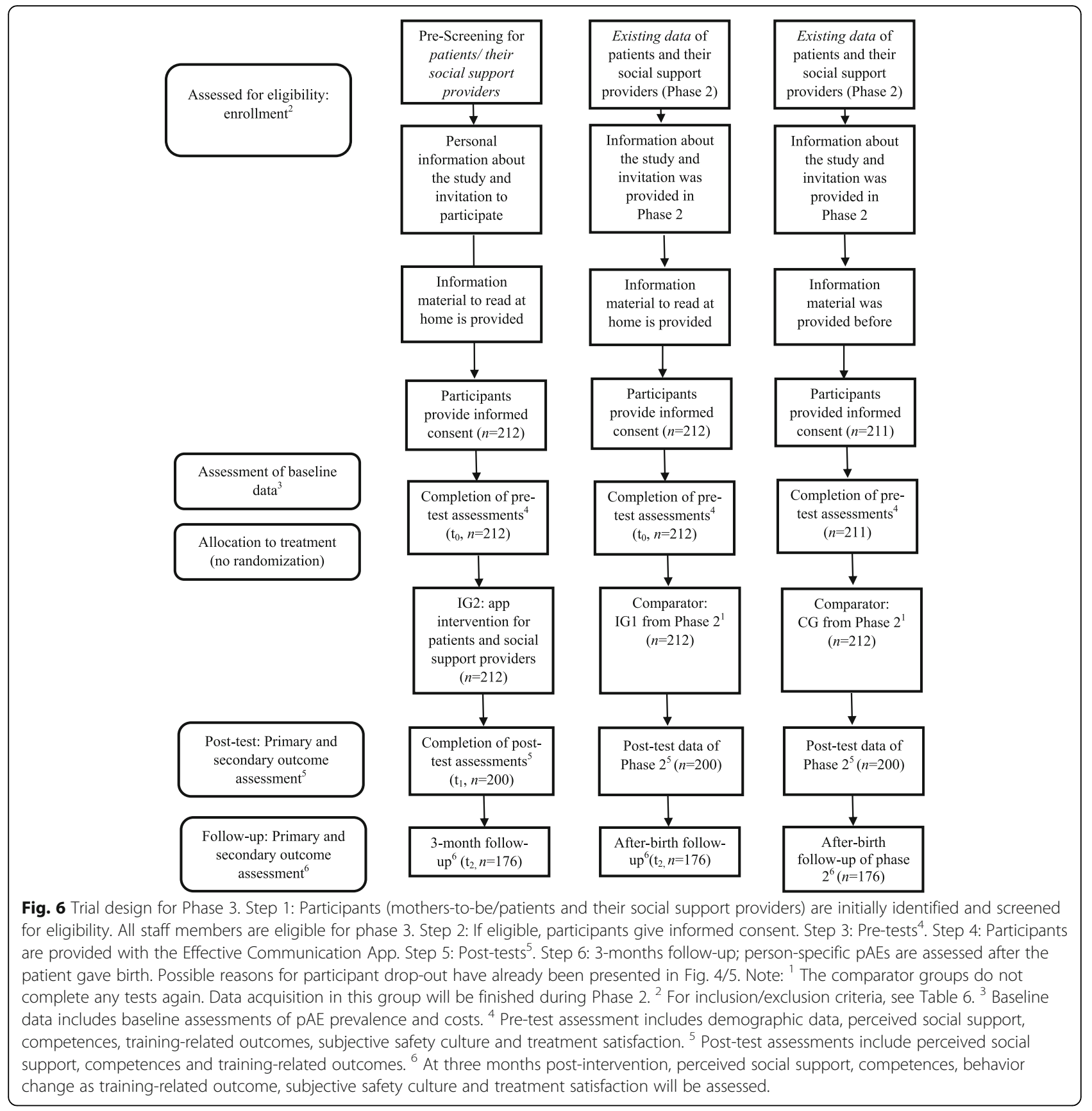

\section{Abbreviations}

BCT: Behavior change techniques; CG: Control group; HAPA: Health Action Process Approach; IG: Intervention group; N/n: Number of study participants: NPWT: Negative-pressure wound therapy; pAEs: Preventable adverse events; RCT: Randomized controlled trial; SACCIA: "Sufficiency", "Accuracy", "Clarity", "Contextualization", and "Interpersonal Adaptation"; SBAR: "Situation", "Background", "Assessment", and "Recommendation"; WHO: World Health Organization

\section{Acknowledgements}

The authors wish to thank Emma Siefring and Nara Skipper for language editing the manuscript and Simon Keller for format editing. The authors wish to thank Kureva Matuku for helping with the literature search.

\section{Authors' contributions}

$S L, J W, H M, F L, C S$ and AH have contributed to the development of this protocol. FMK and CD are PhD students and LK is a research student supervised by SL. SL, JW, HM, FL, CS and AH have contributed developing the analytical strategy and overall methodology. SL, JW, FMK, CD, AW, LK, $H M, F L, C S$ and $A H$ have worked on developing the intervention. SL wrote the first and final draft of the protocol. SL, JW, FMK, CD, AW, LK, KHG, MW, $\mathrm{KE}, \mathrm{KK}$, and CS have contributed to the drafting process. All authors have read and approved the final manuscript.

\section{Authors' information}

Name and contact information for the trial sponsor: Prof. Dr. Sonia Lippke; Professor of Health Psychology and Behavioral Medicine; Jacobs University 
Bremen gGmbH; Campus Ring 1; 28759 Bremen; Germany; Phone: + 49421 200-4730 | Fax + 49421 200-49-4730; s.lippke@jacobs-university.de The role of study sponsor in the study design, data collection, management, analysis, and interpretation of data, writing of the report, and the decision to submit the report for publication is defined as consortium leader. The funder receives all reports but has no ultimate authority over any of these activities because of good scientific practice and independency of the researchers.

\section{Funding}

The study is funded by the Innovation Fund (Project No. 01VSF18023) of the The Federal Joint Committee (G-BA, the highest decision-making body of the joint self-government of physicians, dentists, psychotherapists, hospitals, and health insurance funds in Germany; see https://www.g-ba.de/downloads/17-98-2804/2018-12-04_G-BA_Flyer_Der_Gemeinsame_Bundesausschuss_EN_bf.pdf) with SL as consortium leader. The funding body only observes whether the study is carried out as proposed and approved in terms of study design. The funding body has no influence on the collection, analysis, and interpretation of data. The funding body is not involved in writing the manuscripts but will be informed about the authors' activities.

\section{Availability of data and materials}

The full protocol including data security protocol (in German) and publication guidelines will be available from the corresponding author on reasonable request. Data sharing is not applicable to this article as no datasets were generated or analyzed so far.

\section{Ethics approval and consent to participate}

The research received ethics approval from the University Hospital of UIm Human Research Ethics Committee (Number 114/19), the University Hospital of Frankfurt Medical Research Ethics Committee (Number 19-292) and the Ethics Committee at Jacobs University (dated September 17, 2019). All study participants have to consent in a written form to participate in the study.

\section{Consent for publication}

The paper is not published or under consideration elsewhere. All authors consent the publication of this manuscript.

\section{Competing interests}

When submitting the grant application and receiving the funding statement, JW was working at Die Techniker, but left Die Techniker to join Jacobs University Bremen $\mathrm{gGmbH}$ before the project started. The authors declare that they have no further competing interests.

\section{Author details}

'Jacobs University Bremen gGmbH, Germany Campus Ring 1, 28759 Bremen, Germany. ${ }^{2}$ Die Techniker; Unternehmenszentrale, Fachbereich Versorgungsmanagement, Bramfelder Str. 140, 22305 Hamburg, Germany. ${ }^{3}$ Aktionsbündnis Patientensicherheit, Am Zirkus 2, 10117 Berlin, Germany. ${ }^{4}$ Klinik für Frauenheilkunde und Geburtshilfe, Universitätsklinikum Frankfurt Goethe-Universität, Theodor-Stern-Kai 7, 60596 Frankfurt am Main, Germany. ${ }^{5}$ Universitätsklinikum Ulm, Prittwitzstr. 43, 89075 Ulm, Germany. ${ }^{6}$ Universitätsklinikum Ulm, Albert-Einstein-Allee 23, 89070 Ulm, Germany. ${ }^{7}$ Center for the Advancement of Healthcare Quality and Patient Safety (CAHQS), Faculty of CommunicationSciences, Università della Svizzera Italiana, Lugano, Switzerland.

Received: 6 August 2019 Accepted: 9 October 2019

Published online: 28 November 2019

\section{References}

1. Pronovost PJ, Holzmueller CG, Ennen CS, Fox HE. Overview of progress in patient safety. Am J Obstet Gynecol. 2011;204(1):5-10.

2. Schrappe M. APS-Weißbuch Patientensicherheit. In: Sicherheit in der Gesundheitsversorgung: neu denken, gezielt verbessern [APS Report on Patient safety]. 1st ed. Berlin: Medizinisch Wissenschaftliche Verlagsgesellschaft; 2018.

3. Bartlett G, Blais R, Tamblyn R, Clermont RJ, MacGibbon B. Impact of patient communication problems on the risk of preventable adverse events in acute care settings. CMAJ. 2008;178(12):1555-62.
4. Leonard M, Graham S, Bonacum D. The human factor: the critical importance of effective teamwork and communication in providing safe care. Qual Saf Health Care. 2004;13(Suppl 1):85.

5. Hickson GB, Clayton EW, Githens PB, Sloan FA. Factors that prompted families to file medical malpractice claims following perinatal injuries. JAMA. 1992;267(10):1359-63.

6. Olde Bekkink M, Farrell SE, Takayesu JK. Interprofessional communication in the emergency department: residents' perceptions and implications for medical education. Int J Med Educ. 2018;9:262-70.

7. Lyndon A, Zlatnik MG, Wachter RM. Effective physician-nurse communication: a patient safety essential for labor and delivery. Am J Obstet Gynecol. 2011;205(2):91-6.

8. Antony J, Zarin W, Pham B, Nincic V, Cardoso R, Ivory JD, et al. Patient safety initiatives in obstetrics: a rapid review. BMJ Open. 2018;8(7):e020170.

9. Chang Y, Coxon K, Portela AG, Furuta M, Bick D. Interventions to support effective communication between maternity care staff and women in labour: a mixed-methods systematic review. Midwifery. 2018;59:4-16.

10. Hannawa AF. Disclosing medical errors to patients: effects of nonverbal involvement. Patient Educ Couns. 2014;94(3):310-3.

11. Hannawa A, Wendt A, Day L. New horizons in patient safety: safe communication: evidence-based core competencies with case studies from nursing practice. Berlin: Walter de Gruyter GmbH \& Co KG; 2017.

12. Zech A, Gross B, Jasper-Birzele C, Jeschke K, Kieber T, Lauterberg J, et al. Evaluation of simparteam - a needs-orientated team training format for obstetrics and neonatology. J Perinat Med. 2017;45(3):333-41.

13. Berg CJ, Harper MA, Atkinson SM, Bell EA, Brown HL, Hage ML, et al. Preventability of pregnancy-related deaths: results of a state-wide review. Obstet Gynecol. 2005;106(6):1228-34.

14. November M, Chie L, Weingart SN. Physician-reported adverse events and medical errors in obstetrics and gynecology. In: Henriksen K, Battles JB, Keyes MA, Grady ML, editors. Advances in patient safety: new directions and alternative approaches. Rockville (MD): Agency for Healthcare Research and Quality; 2008.

15. Tanaka K, Eriksson L, Asher R, Obermair A. Incidence of adverse events, preventability and mortality in gynaecological hospital admissions: a systematic review and meta-analysis. Aust N Z J Obstet Gynaecol. 2019;59(2):195-200.

16. Panagioti M, Geraghty K, Johnson J, Zhou A, Panagopoulou E, ChewGraham C, et al. Association between physician burnout and patient safety, professionalism, and patient satisfaction: a systematic review and metaanalysis. JAMA Intern Med. 2018;178(10):1317-30.

17. Welp A, Meier LL, Manser T. Emotional exhaustion and workload predict clinician-rated and objective patient safety. Front Psychol. 2014;5:1573.

18. Welp A, Meier LL, Manser T. The interplay between teamwork, clinicians' emotional exhaustion, and clinician-rated patient safety: a longitudinal study. Crit Care. 2016;20(1):110.

19. Morony S, Weir K, Duncan G, Biggs J, Nutbeam D, Mccaffery KJ. Enhancing communication skills for telehealth: development and implementation of a teach-Back intervention for a national maternal and child health helpline in Australia. BMC Health Serv Res. 2018;18(1):162.

20. Avula R, Menon P, Saha KK, Bhuiyan MI, Chowdhury AS, Siraj S, et al. A program impact pathway analysis identifies critical steps in the implementation and utilization of a behavior change communication intervention promoting infant and child feeding practices in Bangladesh. J Nutr. 2013;143(12):2029-37.

21. Tan DJA, Sultana R, Han NLR, Sia ATH, Sng BL. Investigating determinants for patient satisfaction in women receiving epidural analgesia for labour pain: a retrospective cohort study. BMC Anesthesiol. 2018;18(1):50.

22. Weis J, Zoffmann V, Egerod I. Improved nurse-parent communication in neonatal intensive care unit: evaluation and adjustment of an implementation strategy. J Clin Nurs. 2014;23(23-24):3478-89.

23. Bolognesi M, Nigg CR, Massarini M, Lippke S. Reducing obesity indicators through brief physical activity counseling (PACE) in Italian primary care settings. Ann Behav Med. 2006;31(2):179-85.

24. Omura M, Maguire J, Levett-Jones T, Stone TE. The effectiveness of assertiveness communication training programs for healthcare professionals and students: a systematic review. Int J Nurs Stud. 2017;76:120-8.

25. Schwarzer R. Modeling health behavior change: how to predict and modify the adoption and maintenance of health behaviors. Appl Psychol. 2008;57(1):1-29.

26. Clancy CM, Tornberg DN. TeamSTEPPS: Assuring Optimal Teamwork in Clinical Settings. Am J Med Qual. 2016;22(3):214-7. 
27. Haller G, Garnerin P, Morales M, Pfister R, Berner M, Irion O, et al. Effect of crew resource management training in a multidisciplinary obstetrical setting. Int J Qual Health Care. 2008;20(4):254-63.

28. Nielsen PE, Goldman MB, Mann S, Shapiro DE, Marcus RG, Pratt SD, et al. Effects of teamwork training on adverse outcomes and process of care in labor and delivery: a randomized controlled trial. Obstet Gynecol. 2007;109(1):48-55.

29. Liaw SY, Zhou WT, Lau TC, Siau C, Chan SW. An interprofessional communication training using simulation to enhance safe care for a deteriorating patient. Nurse Educ Today. 2014;34(2):259-64.

30. Hannawa AF, Roter DL. TRACEing the roots: a diagnostic "tool for retrospective analysis of critical events". Patient Educ Couns. 2013;93(2):230-8.

31. Baldwin A, Harvey C, Willis E, Ferguson B, Capper T. Transitioning across professional boundaries in midwifery models of care: a literature review. Women Birth. 2019;32(3):195-203.

32. McEwan D, Ruissen GR, Eys MA, Zumbo BD, Beauchamp MR. The effectiveness of teamwork training on teamwork behaviors and team performance: a systematic review and meta-analysis of controlled interventions. PLoS One. 2017;12(1):e0169604.

33. Gittell JH. Relational coordination. In: Cooper CL, Flood PC, Freeney Y, editors. Wiley encyclopedia of management. Atlanta: American Cancer Society; 2015. p. 1-6.

34. Gittell JH, Fairfield KM, Bierbaum B, Head W, Jackson R, Kelly M, et al. Impact of relational coordination on quality of care, postoperative pain and functioning, and length of stay: a nine-hospital study of surgical patients. Med Care. 2000;38(8):807-19.

35. Gittell JH. Relationships between service providers and their impact on customers. J Serv Res. 2002;4(4):299-311.

36. Noseworthy DA, Phibbs SR, Benn CA. Towards a relational model of decision-making in midwifery care. Midwifery. 2013;29(7):e48.

37. Haug S, Meyer C, Dymalski A, Lippke S, John U. Efficacy of a text messaging (SMS) based smoking cessation intervention for adolescents and young adults: study protocol of a cluster randomised controlled trial. BMC Public Health. 2012;12:51.

38. Lippke S, Fleig L, Wiedemann AU, Schwarzer R. A computerized lifestyle application to promote multiple health behaviors at the workplace: testing its behavioral and psychological effects. J Med Internet Res. 2015;17(10):e225.

39. Duan YP, Liang W, Guo L, Wienert J, Si GY, Lippke S. Evaluation of a web-based intervention for multiple health behavior changes in patients with coronary heart disease in home-based rehabilitation: pilot randomized controlled trial. J Med Internet Res. 2018;20(11):e12052.

40. Storm V, Dörenkämper J, Reinwand DA, Wienert J, De Vries H, Lippke S. Effectiveness of a web-based computer-tailored multiple-lifestyle intervention for people interested in reducing their cardiovascular risk: a randomized controlled trial. J Med Internet Res. 2016;18(4):e78.

41. Lippke S, Schwarzer R, Ziegelmann JP, Scholz U, Schüz B. Testing stage-specific effects of a stage-matched intervention: a randomized controlled trial targeting physical exercise and its predictors. Health Educ Behav. 2010;37(4):533-46.

42. Lippke S, Plotnikoff RC. Testing two principles of the health action process approach in individuals with type 2 diabetes. Health Psychol. 2014;33(1):77-84.

43. Lippke S, Corbet JM, Lange D, Parschau L, Schwarzer R. Intervention engagement moderates the dose-response relationships in a dietary intervention. Dose-Response. 2016;14(1):1559325816637515.

44. Sprangers S, Dijkstra K, Romijn-Luijten A. Communication skills training in a nursing home: effects of a brief intervention on residents and nursing aides. Clin Interv Aging. 2015;10:311-9.

45. Zhang C, Zhang R, Schwarzer R, Hagger MS. A meta-analysis of the health action process approach. Health Psychol. 2019;38(7):623-37.

46. Reyes Fernández B, Lippke S, Knoll N, Blanca Moya E, Schwarzer R. Promoting action control and coping planning to improve hand hygiene. BMC Public Health. 2015;15:964.

47. Lhakhang P, Lippke S, Knoll N, Schwarzer R. Evaluating brief motivational and self-regulatory hand hygiene interventions: a cross-over longitudinal design. BMC Public Health. 2015;15:79.

48. Ernsting A, Gellert P, Schneider M, Lippke S. A mediator model to predict workplace influenza vaccination behaviour--an application of the health action process approach. Psychol Health. 2013;28(5):579-92.

49. Alders I, Smits C, Brand P, van Dulmen S. Does patient coaching make a difference in patient-physician communication during specialist consultations? A systematic review. Patient Educ Couns. 2017;100(5):882-96.

50. Belkora J, Volz S, Loth M, Teng A, Zarin-Pass M, Moore D, et al. Coaching patients in the use of decision and communication aids: RE-AIM evaluation of a patient support program. BMC Health Serv Res. 2015;15:209.
51. Dykes PC, Rozenblum R, Dalal A, Massaro A, Chang F, Clements M, et al. Prospective evaluation of a multifaceted intervention to improve outcomes in intensive care: the promoting respect and ongoing safety through patient engagement communication and technology study. Crit Care Med. 2017;45(8):e813.

52. Ammentorp J, Graugaard LT, Lau ME, Andersen TP, Waidtløw K, Kofoed P. Mandatory communication training of all employees with patient contact. Patient Educ Couns. 2014;95(3):429-32.

53. Emani SS, Allan CK, Forster T, Fisk AC, Lagrasta C, Zheleva B, et al. Simulation training improves team dynamics and performance in a low-resource cardiac intensive care unit. Ann Pediatr Cardiol. 2018;11(2):130-6.

54. Forster AJ, Fung I, Caughey S, Oppenheimer L, Beach C, Shojania KG, et al. Adverse events detected by clinical surveillance on an obstetric service. Obstet Gynecol. 2006;108(5):1073-83.

55. Pettker CM. Systematic approaches to adverse events in obstetrics, part I: event identification and classification. Semin Perinatol. 2017;41(3):151-5.

56. Ellenbecker $\mathrm{CH}$, Byleckie JJ. Home healthcare Nurses' job satisfaction scale: refinement and psychometric testing. J Adv Nurs. 2005;52(1):70-8.

57. Büssing A, Perrar K. Die Messung von Burnout. Untersuchung einer deutschen Fassung des Maslach Burnout Inventory (MBI-D). Diagnostica. 1992;38(4):328-53.

58. Stevenson RJ, Case TI, Hodgson D, Porzig-Drummond R, Barouei J, Oaten MJ. A scale for measuring hygiene behavior: development, reliability and validity. Am J Infect Control. 2009;37(7):557-64.

59. Hellings J, Schrooten W, Klazinga N, Vleugels A. Challenging patient safety culture: survey results. Int J Health Care Qual Assur. 2007;20(7):620-32.

60. Nabhan A, Ahmed-Tawfik MS. Understanding and attitudes towards patient safety concepts in obstetrics. Int J Gynaecol Obstet. 2007;98(3):212-6.

61. Whittal A, Lippke S. Investigating patients with an immigration background in Canada: relationships between individual immigrant attitudes, the doctorpatient relationship, and health outcomes. BMC Public Health. 2016;16:23.

62. Whittal A, Hanke K, Lippke S. Investigating acculturation orientations of patients with an immigration background and doctors in Canada: implications for medical advice adherence. Qual Life Res. 2017;26(5):1223-32.

63. van Sluisveld N, Zegers M, Westert G, van der Hoeven JG, Wollersheim H. A strategy to enhance the safety and efficiency of handovers of ICU patients: study protocol of the plCUp study. Implement Sci. 2013;8:67.

64. Teunissen E, Gravenhorst K, Dowrick C, Van Weel-Baumgarten E, Van den Driessen Mareeuw F, de Brún T, et al. Implementing guidelines and training initiatives to improve cross-cultural communication in primary care consultations: a qualitative participatory European study. Int J Equity Health. 2017;16(1):32.

65. Spitzberg BH, Cupach WR. Disentangling the dark side of interpersonal communication. Mahwah: Lawrence Erlbaum; 2007.

66. Meeks DW, Smith MW, Taylor L, Sittig DF, Scott JM, Singh H. An analysis of electronic health record-related patient safety concerns. J Am Med Inform Assoc. 2014;21(6):1053-9.

67. van Dinter-Douma EE, de Vries NE, Aarts-Greven M, Stramrood CAl, van Pampus MG. Screening for trauma and anxiety recognition: knowledge, management and attitudes amongst gynecologists regarding women with fear of childbirth and postpartum posttraumatic stress disorder. J Matern Fetal Neonatal Med. 2018;18:1-281.

68. Taylor LJ, Adkins S, Hoel AW, Hauser J, Suwanabol P, Wood G, et al. Using implementation science to adapt a training program to assist surgeons with high-stakes communication. J Surg Educ. 2019;76(1):165-73.

69. Karger A, Geiser F, Vitinius F, Sonntag B, Schultheis U, Hey B, et al. Communication skills trainings: subjective appraisal of physicians from five Cancer Centres in North Rhine. Germany Oncol Res Treat. 2017;40(9):496-501.

70. Yu L, Kronen RJ, Simon LE, Stoll CRT, Colditz GA, Tuuli MG. Prophylactic negative-pressure wound therapy after cesarean is associated with reduced risk of surgical site infection: a systematic review and meta-analysis. Am J Obstet Gynecol. 2018;218(2):210-e1.

71. Wang $Y$, Wan $Q$, Lin F, Zhou W, Shang S. Interventions to improve communication between nurses and physicians in the intensive care unit: an integrative literature review. Int J Nurs Sci. 2018;5(1):81-8.

72. Service Delivery and Safety Department, World Health Organization and The Gordon and Betty Moore Foundation. Global Expert Consultation on the WHO Framework on Patient and Family Engagement. WHO, vol. 2014; 2015. p. 27-8.

73. Nigam A, Huising R, Golden BR. Improving hospital efficiency. Med Care Res Rev. 2014;71(1):21-42

74. Wienert J. Understanding health information technologies as complex interventions with the need for thorough implementation and monitoring to sustain patient safety. Front ICT. 2019;6:9. 
75. Bashour HN, Kanaan M, Kharouf MH, Abdulsalam AA, Tabbaa MA, Cheikha SA. The effect of training doctors in communication skills on women's satisfaction with doctor-woman relationship during labour and delivery: a stepped wedge cluster randomised trial in Damascus. BMJ Open. 2013;3(8):e002674.

76. Crofts JF, Bartlett C, Ellis D, Winter C, Donald F, Hunt LP, et al. Patient-actor perception of care: a comparison of obstetric emergency training using manikins and patient-actors. Qual Saf Health Care. 2008;17(1):20-4.

\section{Publisher's Note}

Springer Nature remains neutral with regard to jurisdictional claims in published maps and institutional affiliations.

- fast, convenient online submission

- thorough peer review by experienced researchers in your field

- rapid publication on acceptance

- support for research data, including large and complex data types

- gold Open Access which fosters wider collaboration and increased citations

- maximum visibility for your research: over $100 \mathrm{M}$ website views per year

At BMC, research is always in progress. 